\title{
Retrospective analysis of patiens with brain death
}

\author{
Şermin Eminoğlu๑, Şeyda Efsun Özgünay॰
}

Department of Anesthesiology and Reanimation, University of Health Sciences, Bursa Yüksek Ihtisas Training and Research Hospital, Bursa, Turkey

DOI: $10.18621 /$ eurj.533569

\begin{abstract}
Objectives: We aimed to retrospectively analyze brain death cases in the our intensive care units.

Methods: We examined archive records of brain death cases diagnosed between January 01, 2014 and October 01, 2018. We recorded patients' demographics (age, gender, place of birth, blood type and diagnosis on admission), time to the preparation of the report, additional tests performed, rate of organ donation, donor rate, and number of organs removed.

Results: A total of 151 brain death cases were detected. Of these, 69 were female. The average age was 53.96 \pm 19.52 years. A Rh + was the most common type (39.7\%) in blood type analysis. Intracranial hemorrhage was the primary reason (54.3\%) for admission. Apnea test was performed for 88 patients. Radiological imaging was used in 129 (85.4\%) cases; computed tomography angiography being the most commonly performed method with 79 (52.3\%) cases. Forty four patients' families consented to organ donation. Considering the place of birth for donors, Marmara Region was the leader with 18 (40.9\%) donors. Of the 82 brain death cases diagnosed with intracranial hemorrhage, 35 (42.68\%) donated organs and this rate was significantly high $(p=$ 0.002). The mean follow-up period for brain death was 1.49 days.

Conclusions: Health team is responsible for identifying brain death and shoud be conscious about it, attempting to increase organ donation. They should act rapidly and avoid wasting time after the diagnosis. Family interviews to be conducted by an experienced and trained organ donation coordinator may increase donations by emphasizing the importance of organ donations. Giving wide media coverage to organ donation may increase awareness of the community of organ donation.
\end{abstract}

Keywords: Brain death, intensive care, donor

Received: February 28, 2019; Accepted: May 23, 2019; Published Online: August 15, 2019

$\mathrm{T}$ he advancement of modern medicine provides the patients to recover with organ transplantation, thus the importance of it increases gradually [1]. Organ transplantation occurs in two ways, either from live donors or cadavers. Cadavers are the safest source for transplantation and the heart, pancreas, lungs, small intestine, and cornea are organs that can be obtained from them [2]. In order to perform an organ transplant from a cadaver, the diagnosis of brain death must be established first. Brain death is irreversible loss of all brain functions, including the brain stem, and physiopathological termination of the intracranial circulation. The diagnosis of brain death is a clinical diagnosis in which the presence of irreversible coma, areflexia and apneaare observed [3]. Today, in most of the countries around the world, the criterion of brain

Address for correspondence: Şermin Eminoğlu, MD., Bursa Yüksek İhtisas Training and Research Hospital, Department of Anesthesiology and Reanimation, Bursa, Turkey 
death is accepted and the moment when the brain death occurs is regarded as the moment of death. The most common causes of brain death in adults are anoxic brain injury following the cardiopulmonary arrest, traumatic brain injury, intracerebral hemorrhage, subarachnoid hemorrhage, and ischemic stroke; as for children, they are motor vehicle accidents, asphyxia and child abuse [4]. The diagnostic criteria of brain death in our country were identified by the Ministry of Health [5]. Clinical explanation of the cause of deep coma and absence of the brain stem reflexes, lack of spontaneous breathing efforts, and positive apneatesting are required for the diagnosis, and unanimous consent of two experts, one of which is a neurology or neurosurgery specialist and the other one is an intensive care or anesthesiologyand reanimation specialist, is mandatory. It should be observed that the clinical situation in the first neurological examination, in which brain death is diagnosed, remains samein the second neurological examination performed after 48 hours in infant under two months, 24 hours in children between 2 months and 1 year, 12 hours in children and adults over 1 year of age and 24 hours in anoxic brain deaths. In cases in which individuals under two months are diagnosed with clinical brain death, two supportive tests and in other cases in which individuals are two months old and older, a suitable laboratory method is used to confirm the diagnosis a supportive testshould be performed, there is no need to wait for a second neurological examination [5]. Supportive methods are intended to show that cerebral blood flow is stopped or that brain functions are irreversibly shut down. The gold standard examination is four-vessel angiography [6]. Computed tomography (CT), computed tomography angiography (CTA), magnetic resonance angiography (MRA), transcranial doppler ultrasonography (TCDU), brain scintigraphy and electroencephalography (EEG) can also be performed [7]. Despite all advances in the field of intensive care, the insufficient number of brain death diagnoses and organ donations stands as the most serious problem for patients waiting for organ transplantation. Therefore, it is suggested that the diagnosis of brain death should be made without delay and appropriate donor care should be in place, organ transplant coordinators should visit intensive care units more frequently, and should closely monitor the cases whose Glasgow Coma Scale (GCS) is under seven [8].
In this study, demographic characteristics of the brain death cases detected in the intensive care unit (ICU) of Bursa Yüksek İhtisas Training and Research Hospital, the supportive tests used, the rate of acceptance or rejection of organ donation by families and the rate of use of donated organs will be examined.

\section{METHODS}

The study was performed retrospectively between January 1, 2014, and October 7, 2018, after the approval of the ethics committee (2011-KAEK-25 2018/10-28) by examining the records of all patients who were hospitalized in the intensive care units of our hospital and diagnosed with brain death. Demographic characteristics of the cases, such as age, gender, place of birth, blood type, diagnosis on admission, elapsed time from the moment clinical suspicion of brain death began until the report was prepared, additional tests applied to detect brain death, the rate of organ donation by families, the rate of donors among the cases and the number of organs removed were recorded. The data was obtained by examining archive files and computer records.

\section{Statistical Analysis}

Statistical analyses were performed using the SPSS 21.0 Windows (SPSS, Armonk, New York, IL, USA) software. Variables were expressed as mean, minimum-maximum and percentage.

\section{RESULTS}

In the ICU of the hospital, 151 cases with brain death were identified between January 1, 2014, and October 1, 2018. Of the examined cases, 69 were female and 82 were male. The mean age was $53.96 \pm$ 19.52 (3-87 years), and most of the brain death cases were observed in the age range of 46-64, 62 people (41.1\%). In the blood type of examination, the most common one was A Rh-positive with 39.7\%. Demographic data are shown in Table 1. Of the hospitalized patients, 144 were from the emergency clinic and other services of our hospital and 7 patients were referred from other centers. The admission diagnoses of the patients were evaluated in 5 groups, 
Table 1. Demographic characteristics

\begin{tabular}{|c|c|}
\hline Characteristics & n (\%) \\
\hline \multicolumn{2}{|l|}{ Age groups (years) } \\
\hline $1-17$ & $7(4.6)$ \\
\hline $18-45$ & $36(23.8)$ \\
\hline $46-64$ & $62(41.1)$ \\
\hline $65-74$ & $24(15.9)$ \\
\hline $75-84$ & $17(11.3)$ \\
\hline $85-100$ & $5(3.3)$ \\
\hline Gender, female & $82(54.3)$ \\
\hline \multicolumn{2}{|l|}{ Blood type } \\
\hline $\mathrm{ARh}+$ & $60(40)$ \\
\hline $\mathrm{A} R \mathrm{Rh}-$ & $7(4.7)$ \\
\hline $\mathrm{B} \mathrm{Rh}+$ & $21(13.9)$ \\
\hline $\mathrm{B} \mathrm{Rh}-$ & $4(2.6)$ \\
\hline $\mathrm{AB} \mathrm{Rh}+$ & $7(4.6)$ \\
\hline $\mathrm{AB} \mathrm{Rh}-$ & - \\
\hline $\mathrm{ORh}+$ & $48(31.8)$ \\
\hline $\mathrm{O} \mathrm{Rh}-$ & $3(2)$ \\
\hline Region of birth & Brain death/Donor \\
\hline Marmara & $59(39.1) / 18(40.9)$ \\
\hline Aegean & $13(8.6) / 5(11.6)$ \\
\hline Mediterranean & $1(0.7) /-$ \\
\hline Inner Anatolia & $6(4) / 1(2.27)$ \\
\hline Southeast Anatolia & $11(7.3) / 2(4.54)$ \\
\hline East Anatolia & $11(7.3) / 4(4.09)$ \\
\hline Black Sea & $25(16.6) / 9(20.45$ \\
\hline Abroad & $25(16.6) / 5(11.6)$ \\
\hline
\end{tabular}

namely intracranial hemorrhage, occlusive cerebrovascular accident (CVA), brain tumor, post cardiopulmonary resuscitation (CPR), head trauma and others. Intracranial hemorrhage came first with $54.3 \%$ (Figure 1). Apnea test was performed on 88 patients, but it could not be performed on 63 patients due to hemodynamic instability. Radiological imaging methods were utilized to support the diagnosis in $85.4 \%(n=129)$ of the cases clinically diagnosed with brain death. CTA, MRA, TCDU, diffusion magnetic resonance and cranial CT were applied on $79(52.3 \%)$, $42(27.8 \%), 3(2 \%), 1(0.7 \%)$ and $1(0.7 \%)$ cases respectively. There was no discrepancy between the clinical diagnosis and imaging methods.

Of the 151 cases diagnosed with brain death, 44
Table 2. Organs removed and used

\begin{tabular}{lcc}
\hline Organs & Removed (n) & Used (n) \\
\hline Kidney & 41 & 35 \\
Liver & 45 & 37 \\
Heart & 14 & 5 \\
Lungs & 10 & 6 \\
Cornea & 26 & 24 \\
Pancreas & 3 & 0 \\
Smal bowel & 1 & 0 \\
\hline
\end{tabular}

(29.1\%) approved family donations and 107 (70.9\%) refused. The birth places of donors were evaluated in 8 regions. Marmara region ranked first with 18 $(40.9 \%)$ donors (Table 1).

No statistically significant difference was detected regarding donor and age group, gender place of birth. Of the 82 brain death cases diagnosed with intracranial hemorrhage, 35 (42.68\%) were donors and the patients with intracranial hemorrhage were statistically and significantly higher $(p=0.002)$.

The mean elapsed time to follow brain death was 1.49 days (1-15). Removed from the donors, 6 kidneys, 9 hearts, 8 livers, 4 lungs, 2 corneas, 3 pancreases and 1 small intestine could not be used due to such medical reasons as horseshoe kidney, prolonged period of cold ischemia, eld, unsuitability as a result of biopsy, high troponin value, grade 3 fatty liver, severe sepsis and lack of appropriate recipient. The organs removed from the donors and used were shown in Table 2.

\section{DISCUSSION}

In the world and in our country, organ transplantation is a significant health problem for patients whose treatment and life depend on it. While kidneys and livers can be taken from live donors, single organs such as heart, lung, and pancreas can only be obtained from cadavers. There is a multi-step organ donation process which includes detection of the potential donor, reporting, controlling medical contraindications, donor care, obtaining family approval, removal of organs and directing them to recipients, keeping the removed organs alive in an 


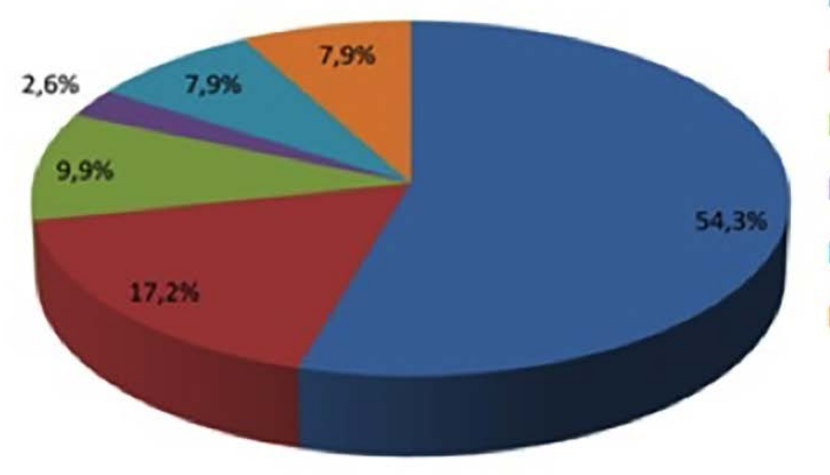

- Intracranial hemorrhage

n Cerebrovascüler disease

Brain cancer

Post CPR

Head trauma

other

Figure 1. The admission diagnoses of the patients.

artificial environment and finally transferring them to the recipient [9]. Donor loss might occur in any of these steps, while it most frequently occurs during the detection of the potential donor, reporting and family approval steps. In order to prevent this, training and motivation of physicians, nurses and health professionals working in ICU in the recognition of brain death and donor care are among fundamental factors.

National and international standardization on brain death diagnostic criteria is provided. In our country, there are two experts in the committee on legal determination of brain death. They are neurosurgery or neurology specialists, and anesthesiology and reanimation specialist. It is of great importance that the people assigned in this commission are welltrained and experienced in the diagnosis of brain death and that the organ transplant coordinators responsible for the family approval step are trained, and that they work in close cooperation with the primary care physician.

The first case of brain death was observed in 2007 in Bursa Yüksek İhtisas Training and Research Hospital. In a study conducted by Karasu et al. [10] between 2007 and 2014, 79 brain deaths were identified and 27 of them were reported to be donors. In our study, the cases with the diagnosis of brain death between 2014 and 2018 were examined. A total of 151 cases were identified and the total number of donations was found to be 44. An increase in the intensive care team and organ transplant coordinator pieces of training throughout the process of the study may have increased the number of brain death determinations.

When the gender of those diagnosed with brain death is referred, the majority of them were male, just like in other studies $[10,12]$. In other studies, the mean age of the cases with brain death was between 40 and 48 years while the mean age of our study was found to be $53.96 \pm 19.52[10,12.13]$.

Battal et al. [12] examined the records of 62 patients diagnosed with brain death. They reported the diagnosis of brain death in an average of 3 days and found the organ donation rate as $29.03 \%$. Karasu et al. [10] reported that $86 \%$ of 79 patients were diagnosed with brain death within the first week of their hospitalization and the organ donation rate was $34.2 \%$. In our study, the diagnosis of brain death was made in an average of $1.49 \pm 1.53$ days and the organ donation rate was found to be $29.1 \%$.

The admission diagnoses of the brain death cases were classified differently in many studies. The most common one was trauma with $58 \%$ in a study by Battal et al. [12] and with $48.3 \%$ in another study [14]. In our study, the most common admission diagnosis was intracranial hemorrhage with $54.3 \%$ as in the study by Karasu et al. [10].

Family approval rate was $34.2 \%$ in a study with 79 notifications in 7 years [10], 69\% in a study with 48 notifications in two years [12], and $29 \%$ in another study with 62 notifications in 4.5 years [15]. In our study, family approval could be obtained from $29.1 \%$ of the cases. This explicit difference in family approval may be due to the experience of the hospital staff and cultural differences in the regions. In our study, the birthplaces of the donor cases were 
examined in 8 different regions and 18 donors were from the Marmara region, which made it take the first place with $40.9 \%$. In other studies, no evaluation was made in terms of the place of birth.

In our study, the blood types of 151 cases with brain death were investigated. A Rh-positive blood type was found the highest with $39.7 \%$.

Once brain death is detected, auxiliary methods may be required to confirm the diagnosis $[16,17]$. In our study, radiological imaging methods were utilized to confirm the diagnosis in $85.4 \%(n=129)$ of the cases diagnosed with brain death. The most commonly used method was CTA with seventy-nine (52.3\%) cases.

2046 brain death cases were reported according to the 2017 data in Turkey. Family approval was obtained in $357(28.45 \%)$ of these cases. In our hospital, family approval was obtained from $11(30.5 \%)$ of 36 brain death cases that were reported in 2017. Family approval in our study was $29.1 \%$ which is similar to the general population [18].

Spain was reported as the country with the highest donor rate in the world. In 2017, in Spain (population $=46.4$ million), there were 2183 donations from cadavers, PMP (per million population) value was 47 , and in Turkey (population $=80.7$ million), there were 554 donations from cadavers, PMP value was 6.9 [18]. This low rate in our country cannot be overcome only by raising awareness of health personnel. It is vital that the Ministry of Health, health directorates and hospital administrations establish the necessary authority.

\section{Limitations}

The limitations of this study were its retrospective nature, the lack of detailed analysis of the causes of family refusal in non-donor cases, and the fact that the time between the diagnosis of BD and cardiac arrest in non-donors was not recorded as data.

\section{CONCLUSION}

Our study shows that the diagnosis of brain death has increased, but we think that there is still need to raise awareness of people about perceiving and approving organ donation and that training, programmes by media related to this subject should be extensively increased. An experienced and trained organ transplant coordinator should try to explain that brain death brain death is a real death during family interviews, and the significance of organ donation should be emphasized and donation rates should be increased. The results of the study may be a guide in determining the missing and inadequate points.

\section{Author's contribution}

Idea/concept = ŞE, ŞEÖ; Check = ŞEÖ; Welding and function: ŞE, ŞEÖ; Materials = ŞE; Data collection and/or processing = ŞE; Analysis Comment $=$ ŞE, ŞEÖ; Literature screening $=$ ŞE, ŞEÖ; Article writing: ŞE; Critical review $=$ ŞEÖ and Responsible author $=$ ŞE.

\section{Conflict of interest}

The authors disclosed no conflict of interest during the preparation or publication of this manuscript.

\section{Financing}

The authors disclosed that they did not receive any grant during conduction or writing of this study.

\section{REFERENCES}

[1] Koçak Süren Ö. [Legal and ethical examination of organ and tissue transplantation]. TBB Dergisi 2007;73:174-95. [Article in Turkish]

[2] Akbaş T, Kurtpınar Z, Senadım S, Coban E, Ozkubat V, Bayrak SK, et al. [Analysis of the patients who had brain dead diagnosis in a neurological intensive care]. ACU Sağllk Bil Derg 2018;9:309-13. [Article in Turkish]

[3] Sabancı PA, Karasu A, Karadereler S, Barlas O. [Diagnosis of brain death]. Sinir Sistemi Cerrahisi Derg 2008;1:81-5. [Article in Turkish]

[4] Izdeş S, Erkılıc E. [Brain death]. Turkish Medical Journal 2007;1:173-9. [Article in Turkish]

[5] Organ ve doku alınması, saklanması, aşılanması ve nakli hakkında kanun. Kanun Numarası 6514 Resmi Gazete 18.01.2014-28886.

[6] Young GB, Shemie SD, Doig CJ, Tettelbaum J. Brief review: the role of ancillary tests in the neurological determination of death. Can J Anaesth 2006;53:620-7.

[7] Unal A, Dora B. [Transcranial Doppler ultransonography as a confirmative diagnostic test in brain death: a review]. Turk J Cerebrovasc Dis 2012;18:49-58. [Article in Turkish]

[8] Erdoğan A. [Donor care in intensive care unit]. S.D.Ü Sağllk Bilimleri Enstitüsü Dergisi 2013;4:136-9. [Article in Turkish] [9] Schauenburg H, Hildebrandt A. Public knowledge and attitudes onorgan donation do not differ in Germany and Spain. Transplant Proc 2006;38:1218-20. 
[10] Karasu D, Yılmaz C, Karaduman İ ,Çınar YS, Pekel NB. [Retrospective analysis of patients with brain death]. Dahili ve Cerrahi Bilimler Yoğun Bakım Dergisi 2015;6:23-6. [Article in Turkish]

[11] Tatlıdil R, Güney İB, Sanlı EÇ,Yüğünt İ, Öner SÖ. [Brain death: Mersin state hospital experience]. Turk J Nucl Med 2010;19:126-31. [Article in Turkish]

[12] Battal M, Horoz A, Karatepe O, Çitgez B. [Experience of research hospital in determination of brain death]. Şişli Etfal Hastanesi Tıp Bülteni 2013;47:59-62. [Article in Turkish] [13] Jansen NE, van Leiden HA, Haase-Kromwijk BJ, Hoitsma AJ. Organ donation performance in the Netherlands 2005-08; medical record review in 64 hospitals. Nephrol Dial Transplant 2010;25:1992-7.

[14] Guzeldağ S, Koca U, Ergör OA, Akan M. [Retrospective analysis of adult brain death cases]. Turkiye Klinikleri J Med Sci 2014;34:47-52. [Article in Turkish]
[15] Kıraklı C, Zeren Uçar Z, Anıl AB, Özbek İ. [The effect of shortening confirmed brain death diagnosis time on organ donation rates in the intensive care]. Dahili ve Cerrahi Bilimler Yoğun Bakım Dergisi.2011;1:8-11. [Article in Turkish]

[16] Wijdicks EF, Varelas PN, Gronseth GS, Greer DM; American Academy of Neurology. Evidence-based guideline update: determining brain death in adults: report of the Quality Standards Subcommittee of the American Academy of Neurology. Neurology 2010;74:1911-8.

[17] Facco E, Munari M, Gallo F, Volpin SM, Behr AU, Baratto $\mathrm{F}$, et al. Role of short latency evoked potentials in the diagnosis of brain death. Clin Neurophysiol 2002;113:1855-66.

[18] International donation and transplantation activitiy, from global observatory on D\&T. (Newsletter Transplant of the Council of Europe 2017): http:// www.transplantobservatory.org/Pages/home.aspx 